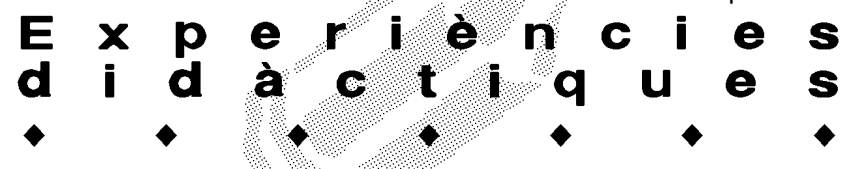

\title{
SEMINARI COMPARATIU DE LLIBRES FRANCESOS, CATALANS I ESPANYOLS DE CIÈNCIES SOCIALS: CONTINGUTS I COMPETÈNCIES
}

\author{
Pilar Almagro Cantón, Estel Masip Miquel i Mireia Rubio Vidal. \\ Alumnes de $2 n$ curs de l'Ensenyament de Mestres (Educació Primària) \\ Cristina Bujeda Hernández i Marta Roqué Secall. \\ Alumnes de 2n curs de l'Ensenyament de Mestres (Llengua Estrangera)
}

\section{Introducció i objectius}

El passat 26 d'octubre a la Facultat de Ciències de l'Educació i Psicologia se celebrà el seminari que encapçala aquestes ratlles, sota la coordinació del professor Antoni Gavaldà, conduït per ell mateix i per la professora francesa Nicole Darmon, de l'Ecole Aérogare de Blagnac. El seminari, obert a tots els alumnes de segon de Magisteri, es va impartir en dues tandes: una al matí i una altra a la tarda, en un format de tres hores per a cada grup de treball.

A la sessió del matí es treballà la prehistòria amb material francès per a nens i nenes de 8-9anys, a partir del llibre Multilivre CE2, Ed. Istra, 2003 i Multilivre CM1 de la mateixa editorial, i amb material del llibre català Espais. Coneixement del Medi, de l'editorial Bruño, 2000. A la sessió de tarda s'abordà un tema de Geografia, la població, a partir del llibre Les ateliers Hachette présentent CM1, per a alumnes de 9 anys, i el llibre Paisajes. Conocimiento del medio, de l'Ed. Bruño, 2000, en castellà, pensat per a alumnes de 10 anys. Alhora es donaren breus pinzellades d'una unitat d'educació cívica, en francès i en català, centrada en els valors d'igualtat $i$ diferència, diferents pobles i cultures, marginats 0 acceptats, i violència i formes de preveure-la per tal que no succeeixi.

El seminari pretenia contrastar diversos aspectes, que sintetitzem:

- El nivell dels continguts dels llibres francesos i dels llibres catalans i espanyols, existents al mercat, exemplificats en uns casos concrets. En els continguts es volia precisar a quins conceptes es donava més importància, el grau de dificultat amb què es presentaven, el que es demanava als alumnes i com es presentava l'avaluació.

- Discernir la metodologia de treball amb què es presentava cada unitat, per captar què es pretenia, a partir d'uns objectius ja marcats per l'editorial.

- Establir el lligam que hi havia entre el discurs del llibre, els exercicis, les imatges, amb les competències que avui dia estan tant en boga.

- Proposta de reformular alguns apartats de text -per vocabularis massa alts de nivell, per excessiva informació, per preguntes no del tot ben formulades...-, i també d'exercicis, buscant que els alumnes aprenguessin a pensar en problemes preparats a l'efecte.

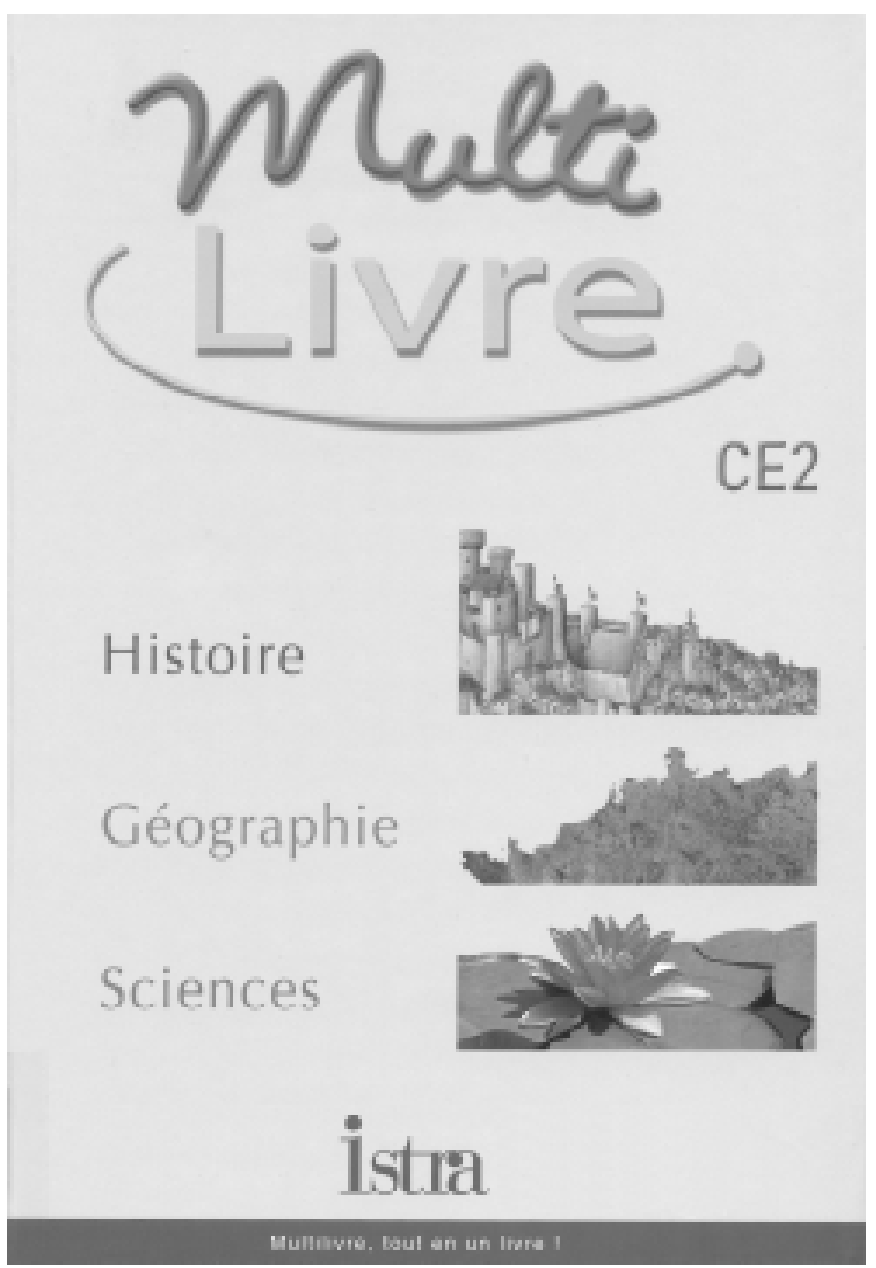




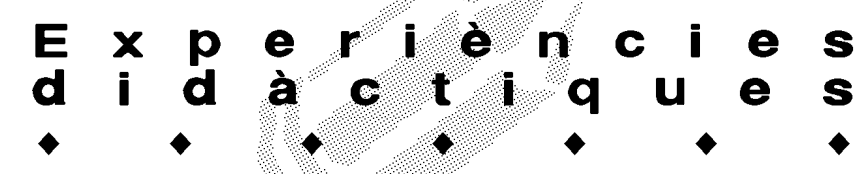

- Finalment es volia contemplar l'enfocament entre preguntes obertes i tancades, suggeriments per avançar i buscar informació, etc.

\section{Alguns aspectes del sistema educatiu francès i es- panyol}

Creiem que per arribar a ser un bon mestre el primer és saber, i després intercanviar experiències, veure formes d'actuar i saber fer ús de material. Aquesta seria la finalitat i el planteig del seminari que realitzàrem.

El primer que se'ns explicà va ser una petita presentació del sistema francès del que anomenem primària, que està dividit en tres cicles. El primer comprèn els nens de 2 a 5 anys $\mathrm{i}$ està dividit en petits, de 2 a 4 anys, i en mitjans, de 4 a 5 anys. El segon cicle va des dels 5 fins als 8 anys. En la primera etapa d'aquest trobem els nens de 5 a 6 anys, considerats com els grans, com a continuació del primer cicle. A la segona etapa es fa un curs preparatori per als alumnes de 6 a 7 anys i el curs elemental 1 per als alumnes de 8 a 9 anys. El tercer cicle són dos cursos mitjans que realitzen els alumnes de $9 \mathrm{a}$ 11 anys. Cal convenir que, en tot aquest procés, els alumnes només poden repetir un curs. Si es dóna el cas que un alumne ha de repetir per segona vegada, se'l deixa promocionar.

Tal i com ens va dir la professora Darmon, un alumne de primer cicle que porta mala base en la lectoescriptura, no podrà realitzar, de manera tan eficient, el seu en- senyament posterior. D'aquí la importància de la llengua en aquest primer cicle. Altrament, un nen que repeteix al tercer cicle ja saben que tindrà dificultats greus a superar, per la qual cosa se li ha de fer una preparació personalitzada per mirar que s'integri al sistema.

Un altre punt que la professora Darmon ens va explicar va ser com s'arriba a ser mestre a França. Aquest procés de formació s'inicia un cop finalitzat el batxillerat. Primer s'han de cursar 3 anys d'universitat estudiant una llicenciatura i, més tard, si volen ser mestres, han de realitzar l'especialització en psicopedagogia. Un cop assolits els objectius, obtenen el diploma. El següent pas és presentar-se a les oposicions, les quals requereixen un nou any de formació. A aquest any de formació postuniversitària s'hi presenten molts llicenciats per a poques places. Les oposicions es realitzen per sectors i la formació inclou matèries com ciències, història, geografia, música i idiomes. Per a passar les oposicions és imprescindible aprovar les matèries de matemàtiques $i$ francès. Una vegada superat el primer any, el segon es basa en disciplines de didàctica i de psicopedagogia, en un sentit tant teòric com pràctic. En aquesta darrera part els futurs mestres realitzen tres sessions pràctiques a la setmana tant en l'educació infantil com en la primària. Superades les proves de les oposicions, els mestres passen a formar part del sistema educatiu francès $i j a$ reben un salari. Remarcà que en els darrers anys hi ha hagut una forta demanda de professors d'idiomes, que no s'ha

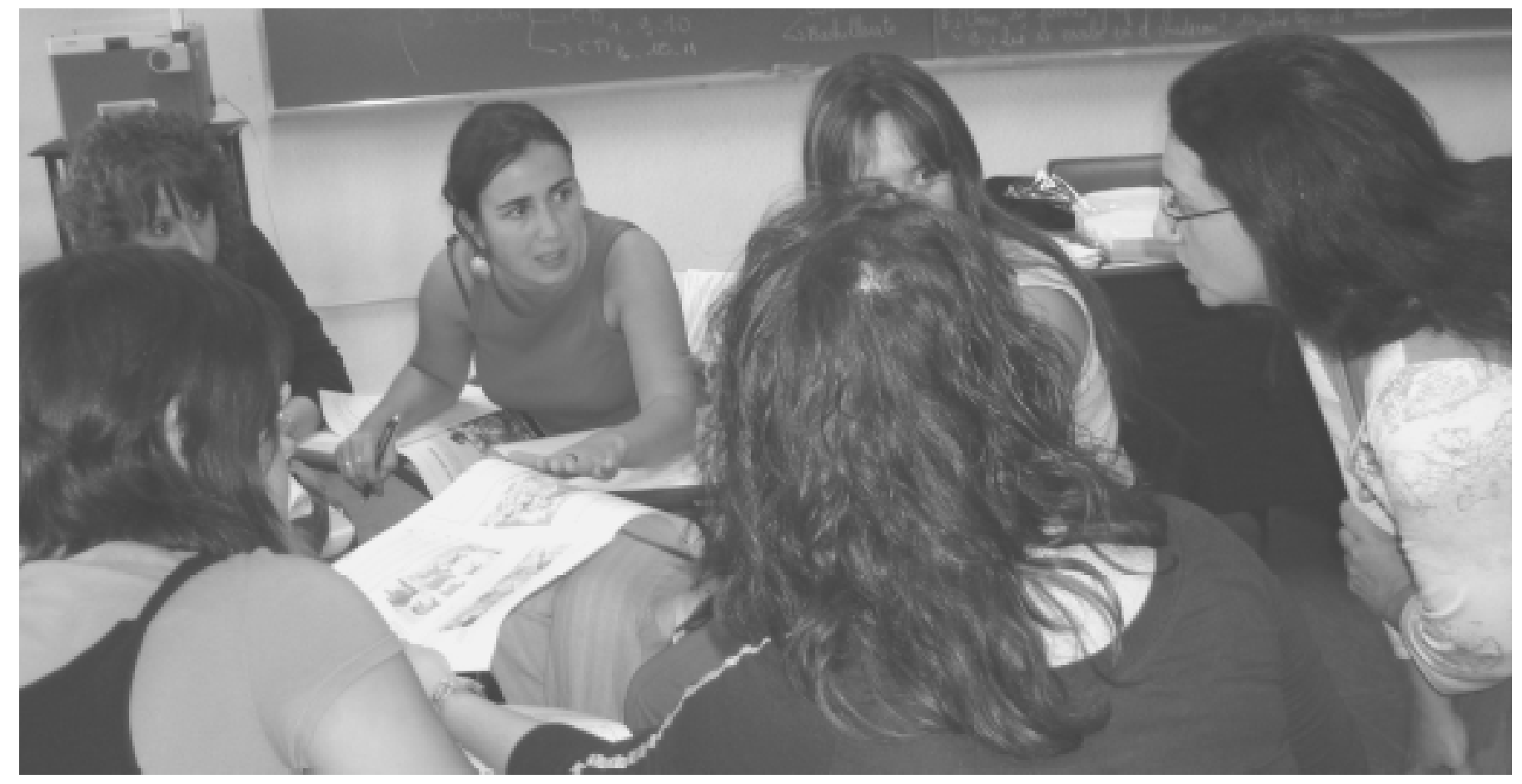




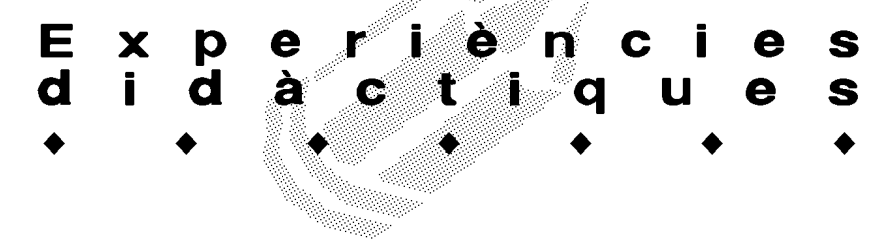

pogut cobrir amb els professors especialitzats, per la qual cosa s'ha hagut de recórrer a mestres que tinguessin coneixements de llengües estrangeres.

Pel que fa referència a Espanya, un cop finalitzat el batxillerat i superades les PAU, es pot accedir a Magisteri a partir d'una determinada nota de tall, amb la possibilitat de cursar diverses especialitats. En general, n'hi ha tres: Infantil, Primària i Especial, comentant-se que els mestres exerceixen la seva professió havent rebut una adequada formació didàctica i psicopedagògica, notant-se que cada cop més el nivell de coneixements sobre les matèries a ensenyar i la cultura general del mateix mestre és més baixa. Després d'obtenir la titulació, es pot entrar a la funció pública o a la privada. En el primer cas s'han d'aprovar unes oposicions, tot i que la via més fàcil és treballar com a mestre interí o fent suplències. Per a les oposicions hi ha un temari obligatori en castellà i català, amb diverses proves eliminatòries. Per al segon cas, per treballar a la privada no es necessita res més que trobar feina.

\section{L'esquema del seminari}

El seminari es va impartir en dos formats, essent semblants quant a disseny però diferents quant a contingut, atès que les unitats que es treballaren van ser diferenciades.

La mecànica de treball va consistir en:

- Lliurament de competències de les Ciències Socials de França. Comprensió dialèctica de cada una d'elles per al treball posterior que es plantejaria.

- Presentació de la mateixa unitat en un llibre francès i en un llibre català, en fotocòpia, per grups de treball. La unitat en francès, sencera, estava traduïda al castellà, aspecte que ens va permetre poder captar tots els detalls, atès que la tercera llengua de la majoria dels alumnes era l'anglès. Lectura de la unitat, en grup, dels exercicis i de les imatges dels llibres en francès i en català.

- Comentari en grup i en seminari sobre la lectura de les dues unitats. Primera aproximació i comparança entre les dues, aclariment d'expressions o de vocabulari que poguessin resultar dificultoses.

- Anàlisi sobre quins objectius pretenien les referides unitats per especificar quins continguts hi eren inclosos. Diferenciació conceptual entre les dues unitats: semblances i diferències.

- Determinació de quines competències s'adeien, des de la perspectiva de la unitat en francès. Observació sobre si les mateixes competències servirien per a la unitat en català.

- Resolució dels exercicis de cada unitat per veure'n la complexitat que representaven. Discussió raonada del grau de dificultat i observació sobre com es plantejava la forma de treball amb els alumnes.
Totes aquestes qüestions es feren amb una mecànica de treball de grups. Després un representant per grup exposà a la resta les seves impressions, raonaments, i s'establí un debat per enriquir les apreciacions. En aquest context els dos professors orientaven els debats, precisaven concrecions i donaven pautes d'aspectes que calia treballar més des de les aules de didàctica específica.

\section{Resultats de treball a partir d'una unitat}

Com ja s'ha comentat anteriorment, es treballaren temes de geografia, d'història i d'educació cívica. Atès que aquí presentem la pràctica que férem sobre una lliçó, agafarem la que es plantejà sobre la prehistòria.

Els eixos de treball en ambdós llibres implicaven, com a treball previ:

a) Distingir, en el curs de la història, els períodes que convenim que són diferenciats els uns dels altres i situar-los cronològicament.

b) Per a cada període, conèixer diverses formes de poder, els grups socials, algunes produccions tècniques i artístiques.

c) Observar esdeveniments i dates importants. Establir relacions entre personatges i esdeveniments i saber-los situar en el període estudiat.

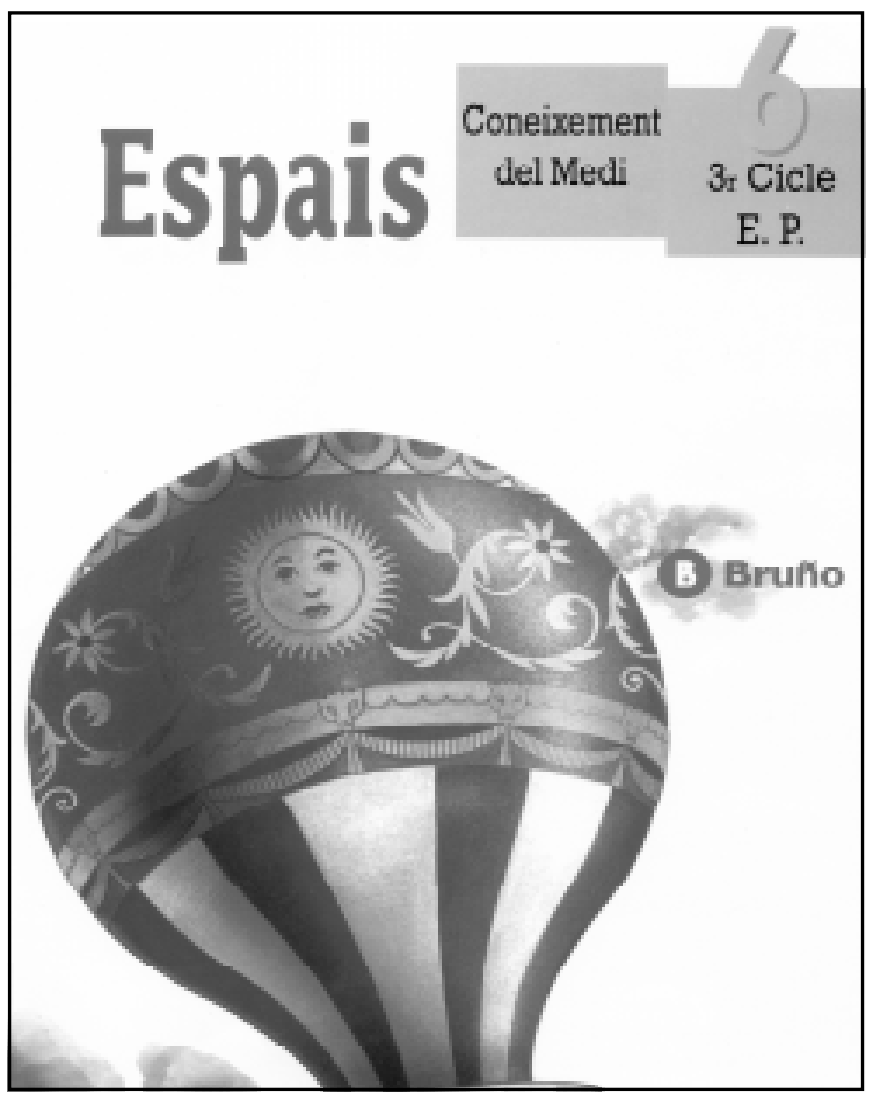




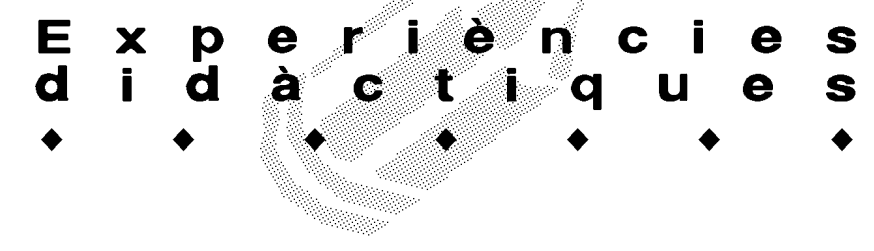

Altrament, feta aquesta primera aproximació, s'analitzaren diversos aspectes:

Un va ser sobre les competències transversals, en relació amb les altres àrees del currículum, en aquesta unitat de la prehistòria. Així, ens adonàrem que a la unitat els dos llibres prestaven molta importància al llenguatge. $\mathrm{A}$ més, el llibre francès també en donava a exercicis on es requerien coneixements matemàtics, exercicis dedicats específicament a la temporalitat. En canvi, en el llibre català ampliava més els conceptes sobre qüestions artístiques i d'utillatge, més de vida quotidiana.

El vocabulari va ser un altre tema d'anàlisi. Constatàrem que el llibre francès era més tècnic 0 específic, $i$ això implicava que l'alumne havia de buscar més recursos per comprendre el temari o fins i tot llegir fora de la lliçó. El llibre català era més planer, semblava més adequat a les necessitats dels alumnes.

Un altre punt que es va tractar va ser el tipus de documents que hi apareixien. En el llibre francès hi havia més varietat de fotografies, dibuixos, gràfics, eixos cronològics... Es treballaven les fotografies com a font d'informació real. Això portava a precisar que l'organització de l'aula seria majoritàriament grupal, tot i que també tenia activitats per realitzar-les individualment. Al llibre català es treballava també a partir de les imatges com dibuixos, fotografies... En el comentari es va poder observar que les imatges eren un suport per a les activitats que hi havia a continuació. Les activitats que es presentaven, tot i ser de tipus grupal, ho eren més per crear debat, observant-se que no hi havia interacció per part del treball de l'alumne amb el seu treball individual.

Respecte del plantejament del tema, el llibre francès començava amb una petita introducció a partir d'una imatge i una avaluació inicial. Tot seguit vindria l'explicació amb les activitats corresponents. Més diferent era el llibre català, ja que aquest començava directament amb l'explicació i seguidament trobàvem els exercicis.

Amb aquesta reflexió es va plantejar quines dificultats es podien trobar els alumnes. El llibre francès es caracteritzava per la dificultat que implicava el llenguatge. Notàrem que era bastant específic, hi havia frases llargues, aspecte que incrementava la dificultat a l'hora de comprendre el significat. Un altre punt dificultós que vam trobar va ser a l'hora de llegir l'eix cronològic, per la dificultat afegida que ens podríem trobar pel fet que no dominessin el sistema mètric.

Un cop observats els aspectes més generals dels llibres, ens vam centrar en les activitats. La primera qüestió va consistir a relacionar el tema amb les competències anteriorment citades. Una vegada resolta aquesta qüestió, es va analitzar la dificultat dels exercicis, tot decidint si n'hi havia algun d'innecessari i, si es donés el cas, per quin el substituiríem. Analitzant tot això es va arribar a la conclusió que el llibre francès presentava una gran varietat i riquesa d'exercicis, ja que aquests feien observar, reflexionar, iniciar i desenvolupar un debat, qüestions que coincidien amb les competències que se'ns havien lliurat. Notàrem que era més reflexiu, i que per tant tenia un nivell de dificultat més alt. En aquest estadi plantejàrem eliminar algun exercici $\mathrm{i}$ el substituiríem per un altre exercici més reflexiu per tal de seguir amb la línia del llibre.

Respecte al llibre català, trobàrem poca varietat i riquesa d'activitats, ja que la gran majoria d'exercicis eren d'observar les imatges i el text, i contestar les preguntes plantejades anteriorment. Eren exercicis que no deixaven lloc que actués la reflexió. Coincidia amb les competències però no vam saber trobar una gran dificultat a l'hora de realitzar les tasques. Alhora decidírem suprimir una pregunta, ja que no trobàvem una relació entre l'observació d'un mapa i l'elaboració de l'activitat, significant, però, que mantindríem l'esperit de la pregunta, ja que provocava reflexió per part dels alumnes

El següent punt que vam tractar va ser com es podria treballar el tema d'història en relació amb les altres assignatures. En aquesta pregunta es va permetre treballar la creativitat de cada grup de treball. Convinguérem que, tot i treballar el temari a partir del llibre, també es necessitaria la utilització d'un quadern on s'hi hauria d'escriure el vocabulari més específic i més difícil d'entendre, les respostes dels exercicis i els conceptes clau que anessin apareixent.

Per finalitzar se'ns va preguntar quin tipus d'avaluació era la més adequada segons els plantejaments dels llibres i la forma d'actuar del mestre. Van sortir diferents alternatives. Sorgiren des de preguntes de reflexió, de relació i d'interpretació, segons el perfil dels alumnes amb qui s'hagués d'actuar.

Del precedent, i després que alguns alumnes realitzessin les dues sessions del seminari, hem arribat a la conclusió que la diferència entre la unitat del llibre francès d'història i del català era ostensible, decantant-nos en aquest tema per treballar amb el llibre francès. En canvi, pel que fa referència al tema de població convinguérem que era més idoni el llibre català. També cal dir que s'acordà que no era primordial el llibre utilitzat, sinó la metodologia aplicada a l'hora de treballar el temari. Com a conclusió, cal significar que la comparança amb altres realitats -en aquest cas, França- va resultar del tot satisfactòria i creiem que s'hauria de potenciar la coneixença de models i de textos de treball per enriquir el bagatge que haurem de tenir com a mestres, en un món en canvi constant. 